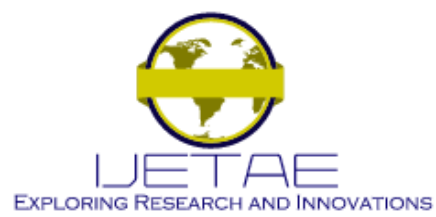

International Journal of Emerging Technology and Advanced Engineering

Website: www.ijetae.com (ISSN 2250-2459, ISO 9001:2008 Certified Journal, Volume 10, Issue 08, August 2020)

\title{
Use of Smartphone Applications in Vibration Analysis: Critical Review
}

\author{
Jefferson da Silva \\ Professor, Mechanical Engineer, Pedro Boaretto Netto State Centre for Professional Education, Paraná State - Brazil
}

\begin{abstract}
Introduction: The use of vibration analysis in the industry has become more and more frequent and has become a powerful tool to guarantee the reliability of machines and equipment. Something that has been noticed, however, is that this technique is restricted to a minority of companies due to the high cost of equipment and specialized labour. Objective: to gather and define a systematic, objective and practical way as main characteristics of the analysis of vibrations by means of smartphones and to propose the possibility of new applications both in the industry and in the mandatory education to popularize it. Methods: A bibliographic search was performed with the search for the term "vibration analysis smartphone apps". Studies with titles not directly related to the research topic, older studies and studies that relate repeated strategies were excluded. Results: It is possible to identify resonance problems, vibration limit violations. Very easy to use and low cost. Conclusion: The use in the academic environment from basic education to higher education is possible due to the simplicity of handling which would make the practice more popular. For application in the industry it is possible to use external sensors and the results from the smartphone. The results found open up several interesting questions for future research. First, it is possible to improve applications as new technologies are developed on smartphones. Second, it is possible to make the technique popular by including its teaching in basic education.
\end{abstract}

Keywords - Smartphone, vibration analysis, MEMS accelerometer, smart devices, Vibration Monitoring.

\section{INTRODUCTION}

Vibratory systems are capable of maintaining a high degree of accuracy even with wide variations in temperature and mechanical vibrations can be caused by the oscillation of the electrical frequency. A study carried out in Germany found that in recent years, smartphones have become increasingly used as multipurpose devices for many simple and fast professional applications and that there are already several mobile applications, which can be used for simple structures for the purposes of analysis or design.
What is almost unknown in the engineering community are the increased capabilities and possibilities of mobile devices to be used in the field of vibration analysis, systems identification and structural monitoring. In addition to advanced performance and increased storage capacity, different hardware components such as accelerometers and gyroscopes have improved considerably [1]. Another important feature of vibration system is whether the ability to remain accurate over velocity.

When the temperature drops, the vibration frequency of a metal vibrating element, such as a tuning fork, will increase mainly due to the thermoelastic coefficient that causes the body to have an increased rigidity to deformation. Smartphones are equipped with several sensors and are capable of measuring various physical phenomena. In addition, they provide communication channels (wireless) that allow for gross, aggregate or precalculated distribution of measurement data. The data processor is compatible with powerful central processor units (CPUs) and relatively large amounts of memory; These features open new and innovative applications. In the engineering area, it is possible to use distributed micro electromechanics based on systems (MEMS) and wireless communication on the sensors to continuously measure vibration and analyse with performance parameters to identify failures. Smartphones present an opportunity to simplify the mobile collection of information about the existing infrastructure, and to streamline the process of saving, transmitting and processing such data. For example, structural vibration measurement allows to identify mechanical oscillations amplitudes and natural frequencies of the structure [2].

Both the base and all the components of the mechanical vibration system need to be well supported and fixed in order for the vibration analyses to be accurate. The most used actuator in an industry is the induction motor, therefore, monitoring to diagnose and predict the condition of the induction motors becomes a high priority task [3]. 


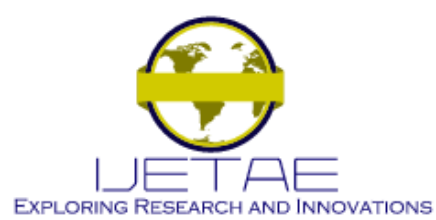

\section{International Journal of Emerging Technology and Advanced Engineering Website: www.ijetae.com (ISSN 2250-2459, ISO 9001:2008 Certified Journal, Volume 10, Issue 08, August 2020)}

Rim and tire imbalance and irregular wheel geometry are common problems in vehicles, which transmit an unwanted vibration in the suspension components and can manifest themselves in the steering and can even cause a fatal accident. In addition, wheel vibration can cause irregular tire tread wear and the presence of vibration due to imbalance is often an indicator related to the development of a major problem. Therefore, vibration analysis with a smart phone is very useful for car maintenance [4].

The damper is an essential component for the system and its efficiency cooperates for the good reading of the vibration amplitude. The study and analysis of vibrations can help to identify some of the main problems in industrial rotating machines, vehicles, appliances and buildings. Technicians use gauges or tools to monitor vibration at regular intervals and report vibration readings in real time. New smart devices have built-in sensors that can assist in vibration analysis and monitoring. Smart devices refer to power computing devices that have a platform that contains a microprocessor and memory and capable of running with an operating system. It can be a smartphone, tablet, smartwatch or any other device. With the growing diffusion and computing power of smart devices, it has become part of the user's daily life activities. In many application areas, smart devices can provide alternative measurement or analysis tools. Obviously, the quality of results based on smart devices with low-cost sensors will not be the same as on dedicated devices with high-quality sensors. However, smart devices can be used as a multipurpose device in numerous applications. In recent years, researchers have been attracted to use the smartphone with low-cost ElectroMechanical Micro Sensors (MEMS) in the field of mechanical vibration analysis, which achieves new achievements day after day. The use of smartphones for vibration analysis allows researchers to develop new applications for the different devices of rotating machines, from small appliances to the level of the industrial plant [5].

One mode of damping of the vibrations used is the deviation of the vibratory energy through the base on which the tuning fork is mounted, which can cause a substantial variation in the frequency of the oscillations generated in the tuning controlled circuit. A bad mass distribution in a rotor will lead to the appearance of the unbalance defect, which causes an undesirable vibration of the rotor, this defect necessarily needs to be corrected. Balancing allows us to control the distribution of masses in a rotor and improve it to keep the forces and vibrations caused by the imbalance within acceptable limits.
The balancing procedure for professional equipment is considered expensive, which leads us to seek to minimize the costs of this operation and be more applicable for professionals and non-professionals. [6].

Another disadvantage of transferring vibrations to the support base is that the mass and elasticity of the base have an effect on the frequency of oscillation, which can cause an undesirable change in frequency and smartphones can also be used to monitor this condition. by measuring threedimensional acceleration in a given space and biaxial displacement in a given plane [7].

In the construction of a flap system, a compact and tightly connected installation is required. In general, a body vibrates when it moves around a reference position according to an oscillatory movement. A vibration can be estimated by measuring the displacement around such a reference or measuring its first and second derivatives, that is, speed and acceleration. The choice of the parameter to be measured is usually dictated by the frequency range of the phenomenon of interest. Considering a sinusoidal movement (that is, a single harmonic) and neglecting the phase, the relationship between the three parameters is determined only by the frequency. In particular, the amplitude of vibration in terms of displacement accentuates components at low frequency more than those at high frequency; conversely, acceleration emphasizes highfrequency components. For measurements at very low frequency $(<1 \mathrm{~Hz})$, displacements are preferable, while for measurements at high frequency $(>100 \mathrm{~Hz})$ accelerations must be detected, even if appropriate techniques have to be chosen according to the application requirements [8].

The purpose of this review is to gather and describe in a systematic, practical and objective way the main strategies used to determine the smartphone application to analyse vibrations and propose new strategies to make its use more popular at all levels in the academic environment since education, since basic education to higher education.

\section{MATERIALS AND METHODS}

\section{A. Search strategy}

For this review, a bibliographic search was made in the month of June 2020 in the online databases ScieLO and Google Scholar for articles published between 01 January 2010 and 31 May 2020. The search was restricted to the descriptor "vibration analysis smartphone apps" in the version English and resulted in 14.300 articles. 


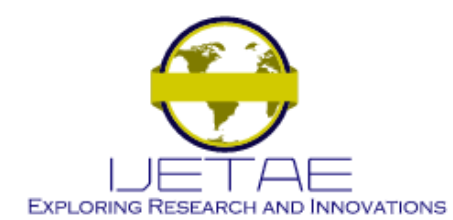

International Journal of Emerging Technology and Advanced Engineering

Website: www.ijetae.com (ISSN 2250-2459, ISO 9001:2008 Certified Journal, Volume 10, Issue 08, August 2020)

\section{B. Inclusion criteria}

The presence of the word "vibration analysis apps for smartphones" in the title of the article was the most relevant criterion. Studies related to smartphone vibration analysis applications have been included and more recent articles presenting new technological trends in smartphone vibration analysis applications have been included. Studies in all languages were included.

\section{Exclusion criteria}

Studies that did not have a title directly related to the research topic were not selected. Studies that did not contain relevant research data in their summary were also excluded. Searches with similar results were also excluded.

\section{Selection of studies}

Through the individual screening of articles found after searching the database using the descriptor used, the main and most frequent strategies for determining the most suitable smartphone applications for analysing vibrations were extracted from the text. Figure 1 shows the organization chart of the methodology for obtaining the 8 articles used for this review. Initially, an analysis was made of the titles of the studies obtained in the research result. The titles directly related to the research with emphasis on analysis by vibration with smartphone passed this initial screening. Then, studies with repeated titles were excluded, selecting the most current ones for reading the summary. If the abstract presented relevant data, the research was selected to read the entire article. The final selection of articles favourable to the theme studied was made by an individual search following the aforementioned inclusion and exclusion criteria.

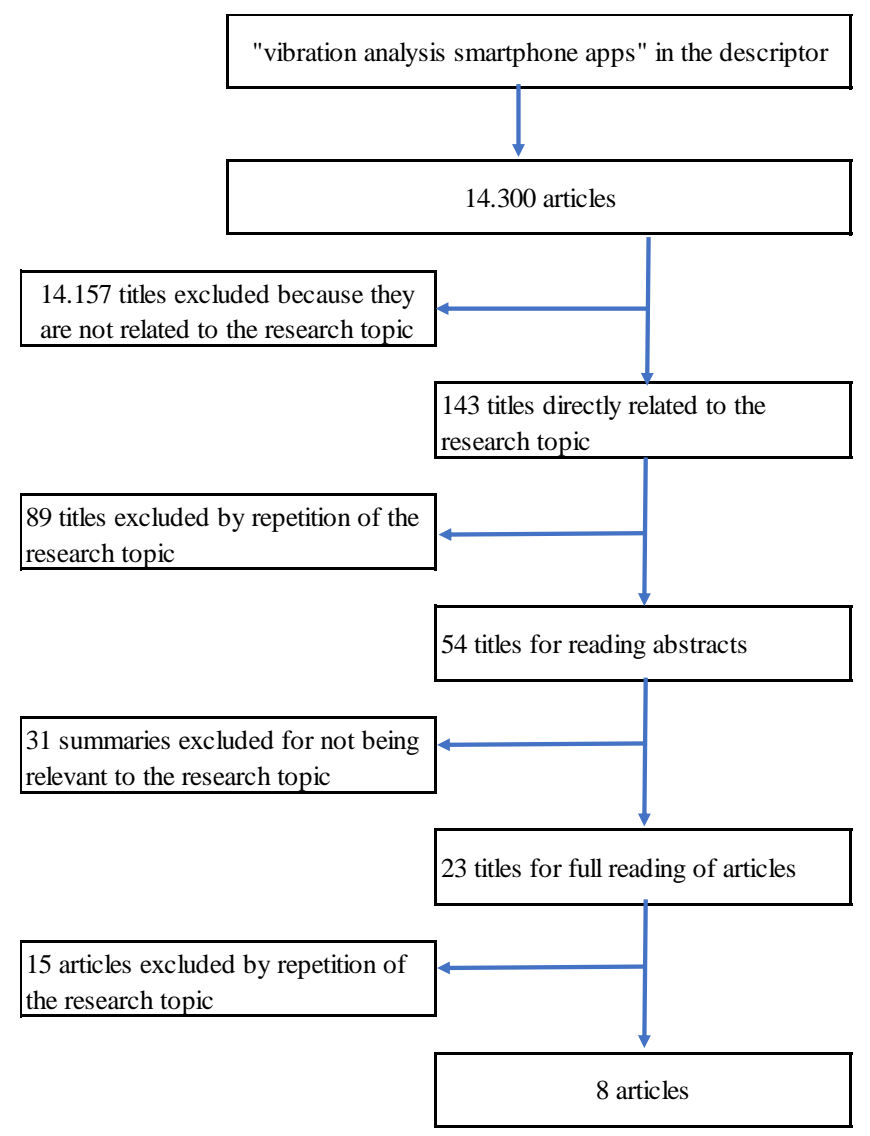

FIGURE 1: ORGANIZATION CHART OF THE METHODOLOGY ON THE DIFFERENT STAGES OF THE SEARCH. 


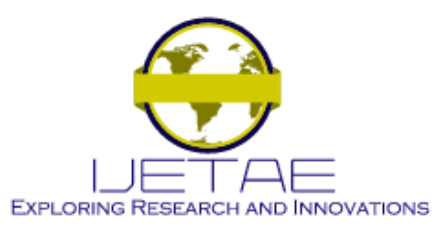

\section{International Journal of Emerging Technology and Advanced Engineering Website: www.ijetae.com (ISSN 2250-2459, ISO 9001:2008 Certified Journal, Volume 10, Issue 08, August 2020)}

\section{RESULTS AND DISCUSSION}

To facilitate the understanding of this study, the main strategies used to determine the applications of smart phones in vibration analysis and the criteria for evaluating their effectiveness were divided into three important pillars: I - Teaching (T) and II - Field (F).
TABLE I presents a main application starting from the most used and decreasing from the main strategies, distributed in each pillar.

TABLE I

STRATEGIES FOR DETERMINING MTB IN THE SCALING PROCESS

\begin{tabular}{lll} 
TEACHING & FIELD & AUTHORS \\
\hline civil Engineering & don't apply & $1,2,7$ \\
\hline industrial mechanical engineering & industrial mechanical engineering & $3,5,6$ \\
\hline automotive mechanical engineering & automotive mechanical engineering & 4 \\
\hline automotive mechanical engineering & don't apply & 8 \\
\hline
\end{tabular}

A free fully functional test / student version of the "iDynamics" application for vibration analysis can be downloaded from the Institute for Structural and Dynamic Analysis at the University of Kaiserslautern [1] which indicates that at a higher-level smartphone are already being used, although on a small scale, in the academic environment. The iDynamics is an app for teaching and learning purposes. With this app any vibration and shock measurements and system identification analyses (e.g. determination of the frequency and damping) can be carried out. The app can also be used to monitor the condition of the "Structural Health Monitoring" structure. Changes in the dynamic properties of the structure (e.g. as a result of damage) can thus be detected and evaluated. The application and use of the "iDynamics" app are intended and intended solely for teaching and learning purposes. The app will be further developed for the aforementioned purposes as necessary. Other uses of the app outside of teaching, in particular for legally binding and mandatory measurements and commercial use, are not permitted or excluded. There was a need to include its use in basic education to popularize the solution.

The method requires that the device is permanently fixed position. That is clear presents a serious restriction on the use of the real world of the proposed methods. The accelerometer is accurate enough, however, oscillation measurement is possible, but limited by the actual operating systems [2].
A proposal to resolve this limitation was presented in a study carried out in Indonesia. The system was composed of IoT nodes with their own power. Each node collects data from $27 \mathrm{~mm}$ thick piezoelectric sensors to the cloud through the router. Motor vibration data was collected using nodeMCU with piezoelectric sensor c. The microcontroller connects to the $\mathrm{Wi}-\mathrm{Fi}$ without requiring modules. The user can monitor the engine vibration from a smartphone [3]. This method has the advantage of doing remote monitoring and also the possibility to power a virtually unlimited amount of equipment 24 hours with a single smartphone.

In the automotive area, it was demonstrated that the accelerometer data collected from a smartphone mounted on the dashboard of a vehicle can successfully be used to detect wheel imbalance in a vehicle [4]. This indicates the opportunity to popularize the use of the technique.

Vibration analysis is growing and developing and becomes an important characteristic to monitor the performance and condition of most of the machines. It could be used to indicate the need for an immediate maintenance or further assessment of causes. The new technology of low-cost MEMS sensors is emerging new trends for vibration analysis where it is facilitating a wider usage for this type of measurements [5]. Which demonstrated the possibility of its application also in the industry depending on the sensor installed on the smartphone. 


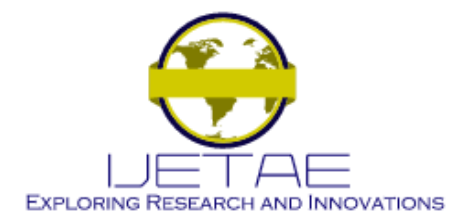

\section{International Journal of Emerging Technology and Advanced Engineering Website: www.ijetae.com (ISSN 2250-2459, ISO 9001:2008 Certified Journal, Volume 10, Issue 08, August 2020)}

In the case of rotors, the "Vibroteak" application allows you to measure the parameters required for the balancing procedure [6].

A study demonstrated the feasibility of using smartphones to monitor the response of a building structure subjected to extreme events, such as earthquakes. The importance of carrying out a practical study to validate the application was also stressed [7]. For this reason, it is important that the inventiveness of such applications starts in basic education.

A study carried out in Italy has shown that the use of smartphones has gained popularity in the past thanks to improvements in efficiency and production quality. In addition, the trend towards regionalization of manufacturing processes (production machines away from the specialized diagnostic office) suggested use of smart devices as easy-to-use, low-cost monitoring tools. The last frontier is the use of built-in accelerometers to make the smart device a stand-alone diagnostic tool. For that, smartphones need to have powerful accelerometers to have a good applicability [8].

\section{CONCLUSIONS}

The excellent studies studied in this review pointed out that the use of vibration analysis by smart phones is already being used successfully in academia, although in a limited way. In this regard, I intend to investigate how to expand the use of the technique even in basic education with the aim of making the technique popular.

A second observed aspect that deserves further research is the fact that it is possible to use the technique in industrial practice, however with certain limitations. This study served as the basis for the second stage of the project, which is to investigate solutions to expand the practice of vibration analysis in the industry.
Solving these two issues, I believe it is possible to overcome the challenge of making technology the most accessible workforce at all industrial and academic levels.

\section{REFERENCES}

[1] Feldbusch, A., Sadegh-Azar, H., Agne, P. 2017. Vibration analysis using mobile devices (smartphones or tablets), Procedia Engineering, Volume 199, 2017, Pages 2790-2795, ISSN 1877 7058, https://doi.org/10.1016/j.proeng.2017.09.543

[2] Höpfner, H., Morgenthal, G., Schirmer, M., Naujoks, M. and Halang. C. 2013. On measuring mechanical oscillations using smartphone sensors: possibilities and limitation. SIGMOBILE Mob. Comput. Commun. Rev. 17, 4 (October 2013), 29-41. DOI: https://doi.org/10.1145/2557968.2557972.

[3] Firmansah, A. e cols. 2019. Self-powered IoT Based Vibration Monitoring of Induction Motor for Diagnostic and Prediction Failure, IOP Conf. Ser.: Mater. Sci. Eng. 588012016 https://doi.org/10.1088/1757-899X/588/1/012016

[4] Siegel, J. E., Rahul Bhattacharyya, Sarma, S. and Deshpande, A. 2015. Smartphone-Based Wheel Imbalance Detection. Volume 2: (October 28, 2015). http://dx.doi.org/10.1115/DSCC2015-9716.

[5] Ali, A., El-Serafi, K., A. K. Mostafa, S. and El-Sheimy, N. (2016) Frequency Features Based Fuzzy System for Rotating Machinery Vibration Analysis Using Smartphones Low-Cost MEMS Sensors. Journal of Sensor Technology, 6, 56-74. doi: 10.4236/jst.2016.63005.

[6] Ait, A. B. A., Touache, A., El Hakimi, A., Chamat, A. 2019. The possibility of using a smartphone in a single plane rotor balancing $\begin{array}{llllll}\text { MATEC Web Conf. } 286 & 03001 & \text { (2019) DOI: }\end{array}$ 10.1051/matecconf/201928603001.

[7] Xie, B.; Li, J.; Zhao, X. Research on Damage Detection of a 3D Steel Frame using Smartphones. Sensores 2019, 19, 745.

[8] De Dominicis, C., Depari, M. A., Flammini, A., Sisinni, E., Fasanotti, L. and Tomasini, M. Performance assessment of vibration sensing using smartdevices, 2014 IEEE International Instrumentation and Measurement Technology Conference (I2MTC) Proceedings, Montevideo, 2014, pp. 1617-1622, doi: 10.1109/I2MTC.2014.6861019. 